\title{
Giant breast hamartoma
}

\author{
M. S. Venkatesh $\cdot$ K. Harish
}

Received: 23 December 2008 / Accepted: 6 January 2009

(C) Association of Surgeons of India 2009

A 14-year-old girl presented with a painless and progressively growing swelling involving the left breast of one year's duration. Physical examination revealed a non-tender well circumscribed lobulated mobile mass in the left breast. Magnetic Resonance Imaging studies revealed a well encapsulated mass lesion in the left breast predominantly containing fat in the upper quadrants (Fig. 1A). T1 weighted images showed randomly oriented hypointense areas within the lesion which turned hyperintense on T2 weighted images with no evidence of increased vascularity. This suggested a benign breast lesion, possibly a hamartoma. The patient underwent excision of the lump through a circumareolar approach followed by mastopexy to correct the ptosis of the breast. The lesion measured $13 \times 9 \mathrm{~cm}$ (Fig. 1B). Histopathology showed lobular ducts surrounded by loose stroma and hyalinized connective tissue along with adipose tissue consistent with fibroadenolipoma (Fig. 2). She is recurrence free after one year follow-up.

Hamartomas of the breast are uncommon benign breast tumours and constitute $0.7 \%$ of all benign tumours of the female breast [1]. Giant breast hamartomas are rarely encountered [2]. Hamartoma of the breast are usually encountered during the fourth and fifth decades. They constitute the

M. S. Venkatesh ${ }^{1} \cdot$ K. Harish ${ }^{2}$

${ }^{1}$ Department of Plastic Surgery

${ }^{2}$ Department of Surgical Oncology

MS Ramaiah Medical College,

Gokula, Bangalore - 560 054,

India

K. Harish $(\bowtie)$

E-mail: drkhari@yahoo.com

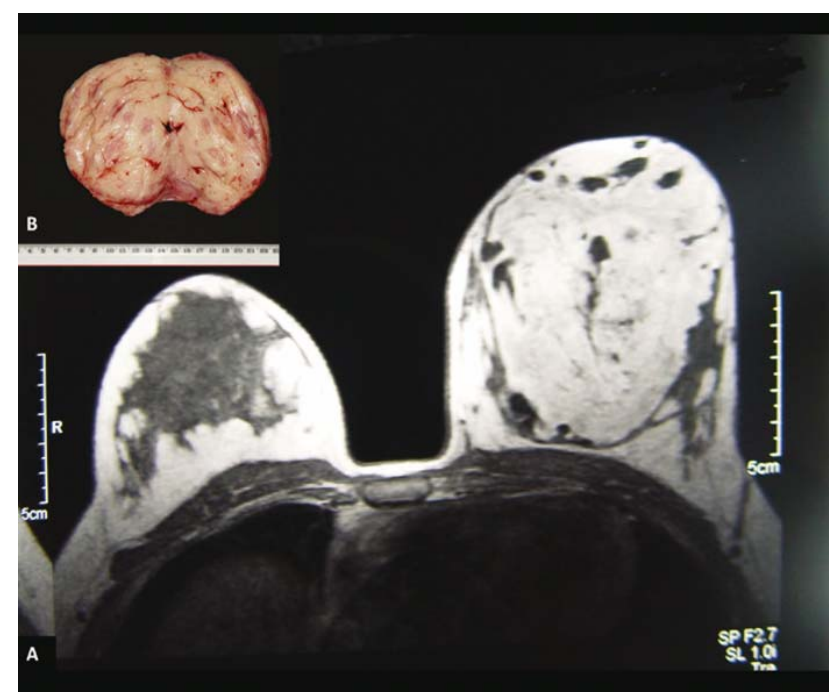

Fig. 1 (A) Magnetic resonance imaging study of breast. (B) The extracted specimen

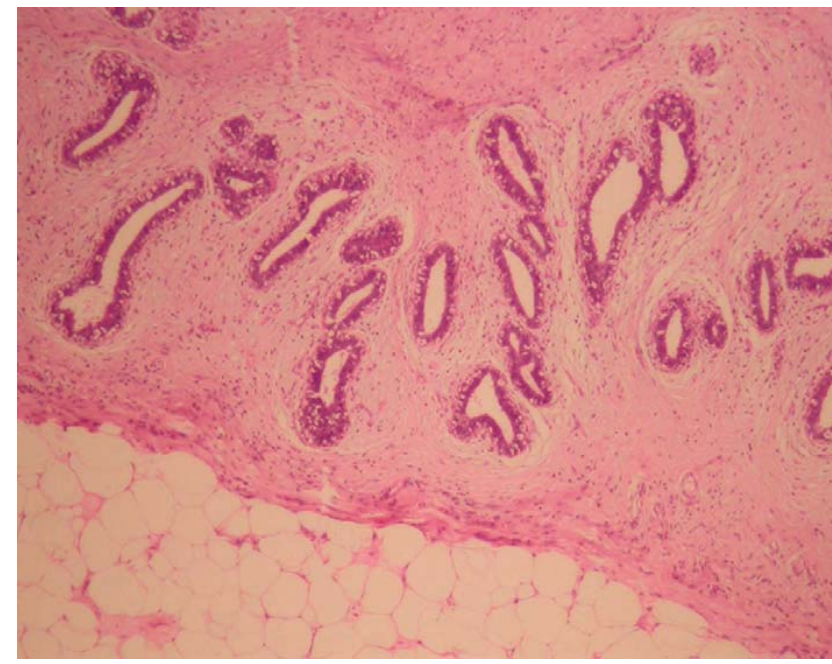

Fig. 2 Histopathology showing lobular ducts 
third most common type of breast lesion after fibrocystic disease and carcinoma. The elements that constitute the hamartomas are fully differentiated, but are abnormally organized. Histologically this heterogenous tumour has been classified into various types based on the predominance of the tissue. The common types include fibrous, fibrocystic, and fibroadenomatous with varying amounts of adipose tissue. Less frequent types are myoid (muscular) and chondroid (cartilage) hamartomas. This patient presented with a giant fibroadenolipoma in the second decade of life.
Conflict of interest The authors do not have any disclosable interest

\section{References}

1. Murat A, Ozdemir H, Yildirim H, Poyraz AK, Ozercan R (2007) Hamartoma of the Breast. Australas Radiol 51: B37-B39

2. Sanal HT, Ersoz N, Altinel O, Unal E, Can C (2006) Giant hamartoma of the breast. Breast J 12(1):84-85 